Business and Economics Research Journal

Volume 9 Number 12018

pp. $49-56$

ISSN: $1309-2448$

DOI Number: 10.20409/berj.2017.88

\title{
BRICS-T Ülkelerinde Politik İstikrar ve Ekonomik Performans İlişsisi Üzerine Bir Analiz
}

\begin{abstract}
Ali Eren Alper
Öz: Bu çalışmada gelişmekte olan ülkelerde politik istikrarın ekonomik büyüme üzerine olan etkisi 1996-2016 arası döneme ait yıllık veri seti kullanılarak incelenmiştir. Panel veri analiz yönteminin kullanıldı̆̆ı çalışmada, geliş̧mekte olan ülkelerde politik istikrarın ekonomik büyüme üzerinde pozitif rol oynadığı tespit edilmiştir. Elde edilen sonuçlara göre politik istikrardaki \%1'lik artş ekonomik büyümeyi \%1.27 arttrmaktadır. Ayrıca modelin tahmin bulgularına göre ekonomik büyümenin, işsizlik oranı, enflasyon oranı ve hükümet harcamaları ile negatif; dışa açıkık ile pozitif ilişkili olduğu belirlenmiştir.
\end{abstract}

Anahtar Sözcükler: Politik İstikrar, Ekonomik Büyüme, Panel Veri Analizi

JEL Sınıflandırması: C23, P48, O40

\section{An Analysis on The Relationship Between Political Stability and Economic Performance in BRICS-T Countries}

\begin{abstract}
In this study, the impact of political stability on economic growth in developing countries is examined using the annual data set of the period 1996-2016. In the study with panel data analysis method, political stability in developing countries is detected to assume a positive role in economic growth. Results Show that, \%1 increase in political stability triggers economic growth by $1.27 \%$. Furthermore, the economic growth of the model is found to be negatively related to the unemployment rate, inflation rate, and government expenditures; while positively related with trade openness according to the estimation findings.
\end{abstract}

Keywords: Political Stability, Economic Growth, Panel Data Analysis

JEL Classification: C23, P48, O40

${ }^{a}$ Asst. Prof., PhD., Nigde Omer Halisdemir University, Faculty of Economics and Administrative Sciences, Department of Public Finance, Nigde, Turkiye, aalper@ohu.edu.tr (ORCID ID: 0000-0003-0008-1202) 


\section{Giriş}

1990 'lı yıllar ülkeler arasındaki ekonomik performansı açıklamak için sadece ekonomik faktörlere bakan araştırmalar yerine sosyal ve politik değişkenlere dayalı olarak yapılan çalışmaların ağılık kazandığı bir dönem olmuştur. Bu dönemde politik istikrarsızlık (politik istikrar) ekonomik performansa zarar veren (destek olan) çok önemli bir unsur olarak görülmüştür. Bu araştırmaların başlangıç noktası büyüme teorisi olmuştur. Geleneksel ekonomik büyüme modelleri sosyal ve politik faktörleri de kapsayacak şekilde genişletilmiştir.

Literatürde politik istikrarsılık kavramına ilişkin iki farklı anlayış vardır. Bu yaklaşımlardan ilki normal ve anormal yollardan gerçekleşen hükümet değişiklikleri, ikincisi ise şiddet olayları askeri darbeler, sivil savaşlar temelinde ortaya çıkan istikrarsızlıklardır (Campos ve Nugent, 2000). Alesina vd. (1996, s. 191) çalışmasında politik istikrarsızığı yönetim gücündeki anayasal veya anayasal olmayan değişim eğilimi olarak tanımlamaktadır. Yönetim gücünün yüksek değişim oranı, ekonomik büyüme performansında düşüşe sebep olacaktir.

Sosyo-politik istikrarsızlık iki kanaldan ekonomiye etki edebilir. Bunlardan ilki politik ve yasal çevrede yarattğı belirsizliktir. i̇kinci etki ise, verimliliğe doğrudan negatif yönde etki ederek piyasa aktivitelerini ve işgücü ilişkilerini bozarak gerçekleşmektedir. Politik istikrarsızlık, politik kutuplaşmanın yüksek olduğu ülkelerde, hükümet değişimi belirsizliğini arttrarak ekonomiye etki edebilir. Hükümet değişimi ihtimalinin artması, bir sonraki hükümetin daha önceki ekonomi politikalarını devam ettireceği görüşü hakim olursa, ekonomiyi çok etkilemeyebilir. Ancak kutuplaşma oranının çok yüksek olduğu ülkelerde hükümet değişimi beraberinde ekonomi politikalarında da ciddi değişimlere sebep olabileceğinden ekonomik aktörler yatırım ve tüketim kararlarını erteleyebilir hatta vazgeçebilir. Bu da ekonomik durgunluğa sebep olabilir. Bu durgunluk üretim faktörlerine erişimi engelleyerek ağır ekonomik sorunlara neden olabilir (Asteriou ve Price, 2000).

Politik istikrarsızlık, politika yapıcıların ufkunu daraltan dolayısıyla da optimal olmayan kısa dönem makro ekonomik politikalar uygulamalarına neden olan bir unsurdur. Bunun sonucunda politika yapıcılar uyguladıkları makroekonomik politikaların yönünü daha sık değiştirmekte ve bu da politika oynaklıklarını arttırmakta ve ekonomik performansı olumsuz etkilemektedir. Politik değişimdeki artş beraberinde siyasi belirsizliği arttracak ve yatırımlar, tasarruf gibi üretimle doğrudan ilişkili ekonomik kararları negatif etkileyecektir. Siyasal değişimin sık yaşandığı ülkelerde yatırımcılar ellerindeki varlıkların gerçek değerini koruyan araçlara yönelmesi, bu ülkelerdeki sabit sermaye yatırımlarının azalmasına, likit ve spekülatif yatırımın artmasına neden olacaktır.

Diğer bir taraftan politik istikrarsızlık ile ekonomik performans ilişkisinin yönü her zaman politik istikrarsızlıktan ekonomik performansa doğru değildir. Düşük ekonomik büyüme de politik istikrara zarar verebilir. Ampirik literatürde birçok çalışmada (Kramer, 1971; Fair, 1978) gelişmiş ülkelerde seçilmiş hükümetlerin tekrar seçilme şanslarının seçim öncesindeki ekonomik büyüme rakamlarına bağlı olduğu belirtilmiştir. Arslan (2011) çalışmasında iktisadi performans ve siyasi istikrarsızık arasındaki teorik ilişki ağını şekil 1'deki gibi göstermiştir.

Politik ortamdaki değişim intimalinin ve dolayısıyla gelecekte uygulanacak politikalardaki belirsizliğin artması ilk olarak ülkedeki riski sevmeyen yatırımcıların üretim kararlarını erteleyecek belki de yatırımlarını yurtdışına çıkararak ülkeden çıkmalarına neden olabilecektir. Çünkü belirsizlik beraberinde vergi oranlarında, toplam talepte, kamu malı arz miktarında, döviz kuru ve enflasyon politikalarında da belirsizliği arttıracaktır. Aynı şekilde ülkeye gelebilecek yeni yabancı yatrımcılar da daha istikrarlı bir politik ortamı tercih edeceklerinden ekonomik kararlarını değiştirebileceklerdir.

Dışa açık gelişmekte olan ülkelerde politik istikrarsızlık sermaye çıkışları aracılığıyla da ekonomik istikrarı etkilemektedir (Lensink vd., 2000). Döviz rezervlerinin düşüklüğü bu kırılganlığın ortaya çıkaracağı olumsuzluğu daha da arttracaktır (Bussiere ve Mulder, 1999). 
Şekil 1. Politik İstikrarsızlık ve İktisadi Büyüme Arasındaki Teorik İlişkiler

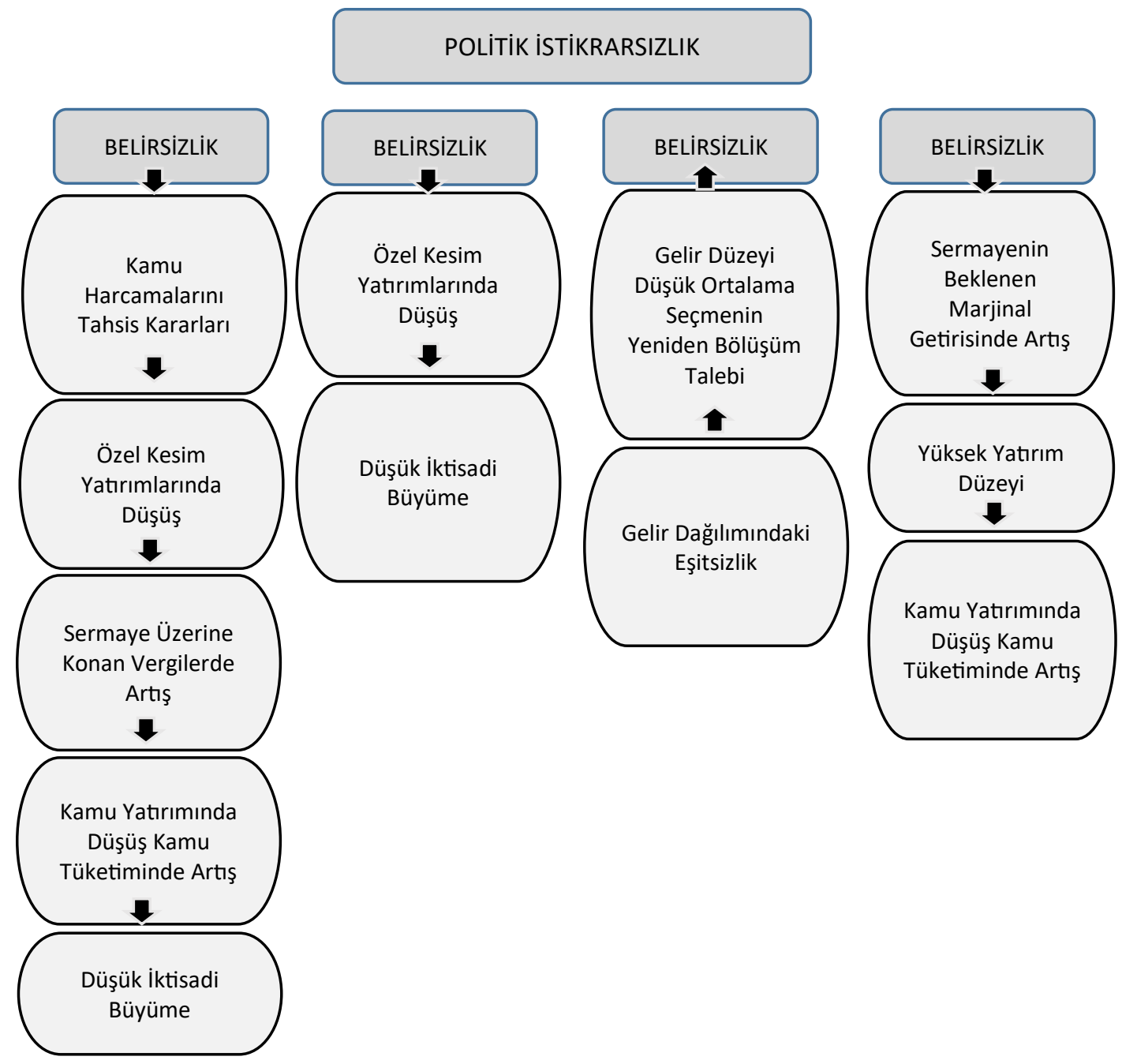

Kaynak: Arslan (2011), s. 13

Bu amaçla çalışmada Brezilya, Rusya, Hindistan, Çin, Güney Afrika ve Türkiye (BRICS-T) için ekonomik büyüme ile politik istikrar, işsizlik oranı, enflasyon, dışa açıkık ve hükümet harcamaları arasındaki ilişkiyi, 1996-2016 dönemine ait yıllık verilerle, panel veri yöntemi ile analiz edecektir. Çalışmanın ikinci bölümünde seçilmiş literatür özeti verilecek, üçüncü bölümde veri seti, model ve ekonometrik yöntem hakkında bilgi verilecek, dördüncü bölümde ampirik sonuçlar belirtildikten sonra son bölümde sonuç ve öneriler aktarılacaktır.

\section{Literatür Taraması}

Büyüme literatüründe mevcut çalışmalar siyasi istikrarsızlık ve ekonomik büyüme ilişkisini farklı yönlerden ele almaktadır. Bazı çalışmalar da doğrudan bir ilişkinin varlığına vurgu yapııırken bazı çalışmalarda aralarında dolaylı bir ilişkinin varlığı savunulmaktadır. Ancak hem teorik hem de ampirik literatürdeki genel eğilim doğrudan veya dolaylı yönden siyasi istikrarsızlığın ekonomik performansa olumsuz etki ettiğidir.

North (1991) çalışmasından itibaren birçok çalışma ekonomik performans ve politik istikrar ilişkisini incelemiştir. North (1991) çalışmasında kurumların standart ekonomik kısıtlar altında karar vericilere bir tercih seti tanımladığını ve bu sayede alışveriş ve üretim maliyetlerini belirlediğini dolayısıyla da ekonomik aktivite de bulunmanın karlıı̆ı̆ı tespit ettiğini belirtmektedir. North (1991)'e göre kurumlar geçmiş ile bugünü ve geleceği bağlayabilmek için hızlanarak evrim geçirmektedir ve tarih ekonomilerin tarihsel performansını açıklayabilmek için kurumların tarihinden oluşmaktadır. 
North (1991) çalışmasından sonra yoğunlaşan politik istikrar ekonomik performans ilişkisi üzerine yapılan ampirik çalışmalar da sonuç farklılıklarının temel sebebi politik istikrarsızlık kavramının tanımında ki farklılıktan kaynaklanmaktadır. Tosun vd. (2008) çalışmasında politik istikrarsızlığın üç farklı yaklaşımla ele alındığını belirtmişlerdir. Bunlar sosyal düzensizlik, miyopi ve kutuplaşma ve zayıf hükümet yaklaşımlarıdır. Politik istikrarsızık ile ekonomik performans arasındaki ilişkiyi inceleyen seçilmiş literatür özeti tablo $1^{\prime}$ de gösterilmiştir.

Tablo 1. Seçilmiş Literatür Özeti

\begin{tabular}{|c|c|c|c|c|}
\hline Yazar(Iar) & Ülke(ler) & Veri Aralığı & Yöntem & Sonuç \\
\hline $\begin{array}{l}\text { Alesina vd. } \\
\text { (1996) }\end{array}$ & 113 ülke & $1950-1982$ & AGLS & $\begin{array}{l}\text { Politik istikrarsızlığın } \\
\text { büyümeye negatif etki } \\
\text { ettiği tespit edilmiştir. }\end{array}$ \\
\hline Feng (1997) & 96 ülke & $1960-1980$ & Üç aşamalı EKK & $\begin{array}{l}\text { Ekonomik büyümenin } \\
\text { politik istikrarsızlık } \\
\text { üzerinde negatif etkisi } \\
\text { bulunmuştur. }\end{array}$ \\
\hline $\begin{array}{l}\text { Asteriou ve Price } \\
(2000)\end{array}$ & Ingiltere & 1961-1997 & EKK ve GARCH & $\begin{array}{l}\text { Politik istikrarsızlığın } \\
\text { büyümeye negatif etki } \\
\text { ettiği tespit edilmiştir. }\end{array}$ \\
\hline Fosu (2001) & Alt Afrika Ülkeleri & $1960-1986$ & $\begin{array}{l}\text { Temel Bileşenler } \\
\text { ve EKK }\end{array}$ & $\begin{array}{l}\text { Politik istikrarsızlığın } \\
\text { büyümeye sermayenin } \\
\text { marjinal ürünü } \\
\text { aracılığıyla negatif etki } \\
\text { ettiği tespit edilmiştir. }\end{array}$ \\
\hline Fielding (2003) & İsrail & $1987-1998$ & $\begin{array}{l}\text { Johansen Eş } \\
\text { bütünleşme }\end{array}$ & $\begin{array}{l}\text { Politik istikrarsızlığın } \\
\text { yatırımlara negatif etki } \\
\text { ettiği tespit edilmiştir. }\end{array}$ \\
\hline Jong-A-Pin (2006) & 98 ülke & $1984-2003$ & $\begin{array}{l}\text { Panel veri } \\
\text { analizi }\end{array}$ & $\begin{array}{l}\text { Politik istikrarsızlığın } \\
\text { büyümeye negatif etki } \\
\text { ettiği tespit edilmiştir. }\end{array}$ \\
\hline $\begin{array}{l}\text { Aisen ve Veiga } \\
(2006)\end{array}$ & 100 ülke & 1960-1999 & $\begin{array}{l}\text { Panel veri } \\
\text { analizi }\end{array}$ & $\begin{array}{l}\text { Politik istikrarsızlığın } \\
\text { yüksek enflasyona sebep } \\
\text { olduğu tespit edilmiştir. }\end{array}$ \\
\hline Tosun vd. (2008) & $\begin{array}{l}\text { Ortadoğu ve } \\
\text { Kuzey Afrika } \\
\text { Ülkeleri }\end{array}$ & $1987-2003$ & Faktör analizi & $\begin{array}{l}\text { Politik risk ile } \\
\text { makroekonomik } \\
\text { performans arasında } \\
\text { negatif ilişki tespit } \\
\text { edilmiştir. }\end{array}$ \\
\hline Arslan (2011) & Türkiye & $1987-2007$ & $\begin{array}{l}\text { Johansen Eş } \\
\text { bütünleşme }\end{array}$ & $\begin{array}{l}\text { Siyasi istikrarsızlık ile } \\
\text { ekonomik performans } \\
\text { arasında uzun dönemli } \\
\text { ilişki tespit edilmiştir. }\end{array}$ \\
\hline $\begin{array}{l}\text { Gür ve Akbulut } \\
\text { (2012) }\end{array}$ & $\begin{array}{l}19 \text { gelişmekte } \\
\text { olan ülke }\end{array}$ & $1986-2003$ & $\begin{array}{l}\text { Panel veri } \\
\text { analizi }\end{array}$ & $\begin{array}{l}\text { Politik istikrar ile } \\
\text { ekonomik büyüme } \\
\text { arasında pozitif ilişki } \\
\text { tespit edilmiştir. }\end{array}$ \\
\hline $\begin{array}{l}\text { Tang ve Abosedra } \\
\text { (2014) }\end{array}$ & $\begin{array}{l}\text { Orta Doğu ve } \\
\text { Kuzey Afrika } \\
\text { ülkeleri }\end{array}$ & 2001-2009 & $\begin{array}{l}\text { Genelleştirilmiş } \\
\text { momentler } \\
\text { yöntemi }\end{array}$ & $\begin{array}{l}\text { Politik istikrarsızlığın } \\
\text { büyümeye negatif etki } \\
\text { ettiği tespit edilmiştir. }\end{array}$ \\
\hline
\end{tabular}




\section{Veri Seti, Model ve Ekonometrik Yöntem}

Çalışmada, BRICS-T ülkelerinde politik istikrar (PS), işsizlik oranı (UE), enflasyon (CPI), dışa açıklık (OP) ve hükümet harcamaları (GE) ile ekonomik performans (GDP) arasında bir ilişki olup olmayacağı araştrılacaktır. Analiz için BRICS-T ülkelerinin seçilmesinin temel nedeni analiz döneminde Dünya Bankası sınıflandırmasına göre bu ülkelerin orta gelir grubuna ait olması ve son 10 yıllık süreçte sanayileşmişülkelerin çok üzerinde bir ekonomik büyüme gerçekleştirmiş olmalarıdır. Ayrıca bu ülke grubu üzerine yapılan çok sayıdaki çalışmalar [Shahrokhi vd. (2017); White vd. (2017); Mamunur Rashid vd. (2017)] bu ülke grubunu spesifik bir örneklem olarak karşımıza çıkarmaktadır. Bu kapsamda, hem gelişmiş hem de gelişmekte olan ülkelerin özelliklerini taşıyan bu grup üzerine ulaşılan bulgular her iki grup ülke içinde sonuçlar ortaya koyabilecek niteliktedir. Çalışmanın verileri Dünya Bankası veri tabanından elde edilmiştir. Dünya Bankası Küresel Yönetişim göstergesi verileri 1996 yılında başladığı için çalışmanın veri aralığı 1996-2016 olarak belirlenmiştir. Çalışma açısından en önemli gösterge olan politik istikrar verisi Dünya Bankası'nın Küresel Yönetişim Göstergesi (WGI) verilerinden elde edilmiştir. WGI verileri 1996 yılından itibaren 200 ülke için 6 kompozit gösterge için hesaplanmaktadır. Bunlar hesap verebilirlik, politik istikrar, hükümet etkinliği, düzenleyici kurumların kalitesi, hukukun üstünlüğü ve yolsuzluğun kontrolü başlıklarıdır. WGı hesaplamaları bireylere uygulanan anket verisi, hükümet dışı organizasyonlar, kamu sektörü organizasyonları ve ticari olarak bilgi sağlayan kurumlar gibi 31 farklı kaynaktan elde edilen birçok değişken üzerine temellendirilmiştir. WGI'da hesaplanan 6 değişkenden çalışmanın analizine dahil olan politik istikrar verisi hükümetin istikrarsızlık olasılıklarını ve anayasal süreçler dışında hükümetin devrilme olasılıklarını göstermektedir.

İssizlik oranı verisi Uluslararası Emek Organizasyonu (ILO) verilerine dayanarak çalışma gücü içerisindeki çalışmayan ancak çalışmaya hazır ve iş arayan kişilerin yüzdesini göstermektedir. Enflasyon verisi ortalama bir tüketicinin, belirli bir mal ve hizmet sepetinin maliyetindeki yıllık değişimi Laspeyres yöntemine göre göstermektedir.

Dışa açıklık verisi 2010 ABD doları cinsinden ithalat ve ihracatın toplamının, 2010 ABD doları cinsinden GSYH'ye oranlanmasıyla bulunmuştur. Hükümet harcamaları değişkeni ise nihai mal ve hizmet alımına yönelik hükümet harcamalarını ifade etmektedir. Ekonomik performans değişkeni olarak ise 2010 ABD doları cinsinden GSYH alınmıştır. Analize dahil edilen değişkenler doğal logaritmik formda kullanılmıştır. Ele alınan değişkenler bakımından analize dahil edilen ülkeler birbirlerine benzer özellikler taşıdıklarından homojen bir örneklem grubu ile ekonometrik çalışma yapılmış olacaktır.

Analize dahil edilen değişkenler ile ilgili tanımlayıcı istatistikler tablo 2'de aktarılmıştır.

Tablo 2. Tanımlayıcı İstatistikler

\begin{tabular}{|l|l|l|l|l|}
\hline Değişken Adı & Min. & Max. & Ortalama & St. Sapma \\
\hline GDP & -6.25 & 13.47 & 4.49 & 4.14 \\
\hline PS & -1.78 & 0.14 & -0.52 & 0.39 \\
\hline UE & 3.72 & 25.78 & 9.93 & 7.01 \\
\hline CPI & -0.84 & 14.98 & 6.42 & 3.63 \\
\hline OP & 21.01 & 71.79 & 47.51 & 11.26 \\
\hline GE & 9.65 & 21.56 & 16.11 & 3.65 \\
\hline
\end{tabular}


Çalışmada tahmin edilecek model denklem 1'de belirtilmiştir.

$$
G D P_{\mathrm{I}, t}=\alpha_{0}+\alpha_{1} P S_{i, t}+\alpha_{2} U E_{i, t}+\alpha_{3} C P I_{i, t}+\alpha_{4} O P_{i, t}+\alpha_{5} G E_{i, t}+\varepsilon_{t}
$$

Panel veri analizi çerçevesinde veriler hem zaman serisi hem de yatay kesit serisi özelliklerini barındırdığı için öncelikle verilerde yatay kesit bağımlıı̆̆ının (CSD) test edilmesi gerekmektedir. Çalışmada CSD'nin tespit edilmesi amacıyla dört farklı test uygulanacaktı. Bunlar Breusch-Pagan LM testi, Pesaran testi, Friedman testi ve Frees testidir. Dört testte de temel hipotez yatay kesit bağımsızlığını ifade ederken, alternatif hipotezler yatay kesit bağımlılığını göstermektedir.

CSD testlerinden sonra serilerdeki zaman serisi özelliklerinin belirlenmesi amacıyla değişen varyansın tespiti için Wald Testi, oto korelasyon sorunu için ise Wooldridge testi uygulanacaktır. CSD, değişen varyans ve oto korelasyon test sonuçlarına göre Uygun Genelleştirilmiş En Küçük Kareler (FGLS) ve Panel Düzeltilmiş Standart Hatalar (PCSE) yöntemleriyle katsayılar tahmin edilecektir.

FGLS yöntemi oto korelasyon ve değişen varyansın varlığında da asimptotik olarak etkin sonuçlar vermektedir. Ayrıca doğrusal modellerde ve hata kovaryans matrisinin bilindiği durumlarda en küçük kareler yöntemine tercih edilmektedir (Hansen, 2007; Taylor, 1977). FGLS yönteminde incelenen model en küçük kareler yöntemiyle tahmin edilmekte, ardından elde edilen kalıntılar oto korelasyon ve değişen varyansı hesaplamak için kullanılmakta ve tekrar genelleştirilmiş en küçük kareler yöntemiyle tahmin yapılmaktadır.

Beck ve Katz (1995) çalışmasına göre PCSE yöntemi karmaşık panel hata yapılarında bile FGLS yöntemine göre etkinlik kaybı olmaksızın daha kesin standart hatalar elde ettiğini belirtmiştir. PCSE yönteminde kalıntıların oto korelasyona sahip olduğu tespit edilirse Prais-Winsten düzeltme yöntemiyle düzeltme yapılarak tahmin sonuçları elde edilmektedir.

\section{Ampirik Sonuçlar}

Yatay kesit bağımlıı̆ı̆ını tespit etmek amacıyla yapılan test sonuçları tablo 3'de gösterilmektedir.

Tablo 1. Yatay Kesit Bağımlılığı Test Sonuçları

\begin{tabular}{|c|c|c|}
\hline Test & Istatistik Değeri & Anlamlılık Değeri \\
\hline Breusch-Pagan & 29.056 & 0.0408 \\
\hline Pesaran & 4.258 & 0.0018 \\
\hline Friedman & 19.016 & 0.0003 \\
\hline Frees & 0.356 & $\begin{array}{ll}\text { Q Dağılımı Kritik Değerleri } \\
10 \% & 0.2136 \\
5 \% & 0.2838 \\
1 \% & 0.4252\end{array}$ \\
\hline
\end{tabular}

Breusch-Pagan LM, Pesaran CD, Friedman ve Frees test sonuçlarına göre değişkenler arasında yatay kesit bağımlılığı tespit edilmiştir.

Tablo 4. Wald ve Wooldridge Test Sonuçları

\begin{tabular}{|l|l|l|}
\hline \multicolumn{1}{|c|}{ Test } & istatistik Değeri & Anlamlılık Değeri \\
\hline Wald Değişen Varyans Testi & 70.67 & 0.000 \\
\hline Wooldridge Oto Korelasyon Testi & 38.28 & 0.001 \\
\hline
\end{tabular}


Tablo 4'de de belirtildiği üzere Wald değişen varyans testi ve Wooldridge oto korelasyon testi sonucuna göre serilerde hem değişen varyans hem de birinci dereceden oto korelasyon sorunu bulunmaktadır.

Elde edilen sonuçlara göre yatay kesit bağımlılığını dikkate alan, değişen varyans ve oto korelasyona dirençli FGLS ve PCSE test sonuçları tablo 5'de verilmiştir.

Tablo 5. FGLS ve PCSE Tahmin Sonuçları

\begin{tabular}{|c|c|c|c|c|}
\hline & \multicolumn{2}{|c|}{ PCSE } & \multicolumn{2}{c|}{ FGLS } \\
\hline Değişken & Katsayı & Olasılık Değeri & Katsayı & Olasılık Değeri \\
\hline PS & 1.27 & 0.022 & 1.34 & 0.011 \\
\hline UE & -0.48 & 0.000 & -0.39 & 0.001 \\
\hline CPI & -0.61 & 0.004 & -0.52 & 0.000 \\
\hline OP & 0.85 & 0.015 & 0.71 & 0.022 \\
\hline GE & -0.32 & 0.000 & -0.49 & 0.000 \\
\hline
\end{tabular}

FGLS ve PCSE tahmin sonuçlarının olasılık değerlerine göre tüm değişkenlerin katsayıları istatistiki olarak anlamlı bulunmuştur. Buna göre politik istikrar endeksinde gerçekleşecek \%1'lik bir artş̧ ekonomik performansta \%1.27'lik bir artıs ortaya çıkartmaktadır. İşsizlik oranlarındaki, enflasyondaki ve hükümet harcamalarındaki \%1'lik bir artış ekonomik performansta sırasıyla $\% 0.48^{\prime}$ lik, $\% 0.61^{\prime}$ lik ve $\% 0.32^{\prime}$ lik bir azalma yaratmaktadır. Son olarak da dışa açıklıktaki \%1'lik artı̧ ekonomik performansı \%0.85 arttırmaktadır.

\section{Sonuç ve Öneriler}

Siyasi istikrarsızlık ekonomistler tarafindan ülkelerin ekonomik performansını baltalayan ciddi bir problem olarak tanımlanmaktadır. Bu ilişkinin perde arkasında iki temel neden bulunmaktadır. Bunlardan ilki belirsizliğin olduğu bir ortamda karar vericilerin ufkunun daralması ve böylece optimal olmayan makroekonomik politikalar ortaya koymaları, ikinci olarak da optimal olmayan bu kararların ekonominin diğer aktörlerini de olumsuz etkilemesidir.

Siyasi istikrar ekonomik performans ilişkisinin teorik temelinde yatan başlıca faktör istikrar ile doğru orantılı geliş̧me gösteren yatırımlar ve bunun etkilediği milli gelir gelişimidir. Bu da doğal olarak kişi başına düşen milli gelirine ve ülke refah seviyesi üzerinde önemli etkiler yapmaktadır.

Bu amaçla çalışmada Brezilya, Rusya, Hindistan, Çin, Güney Afrika ve Türkiye için ekonomik büyüme ile politik istikrar, işsizlik oranı, enflasyon, dışa açıkık ve hükümet harcamaları arasındaki ilişkiyi, 1996-2016 dönemine ait yıllık verilerle, panel veri yöntemi ile analiz edilmiştir.

Elde edilen temel bulgu ekonomik olmayan bir faktör olan siyasi istikrar ve ekonomik büyüme arasında pozitif yönlü bir ilişki olduğudur. Politik istikrardaki \%1'lik bir artı̧, ekonomik büyümeyi \%1.27 oranında arttırmaktadır. Ayrıca modelin tahmin bulgularına göre ekonomik büyüme işsizlik oranı, enflasyon oranı ve hükümet harcamaları ile negatif; dışa açıklık ile pozitif ilişkilidir. Çalışmamızın sonuçları genel olarak değerlendirildiğinde Gür ve Akbulut (2012), Jong-A-Pin (2006) çalışmalarının bulguları ile benzerlik göstermektedir

Analiz sonuçlarının genel bir değerlendirilmesi yapıldığında, politik istikrar ile ekonomik büyüme arasında literatürde iddia edildiği gibi pozitif yönlü ilişkinin gelişmekte olan ülkeler açısından da geçerli olduğu görülmektedir. Bu nedenle gelişmekte olan ülkelerde yapısal dönüşümden sorumlu kurumların bu dönüşümleri gerçekleştirmek için uygulamaya koydukları politikaların, politik istikrarı dikkate alarak, 
istikrarsılı̆̆ı arttırıcı davranışlardan kaçınarak gerçekleştirmesi gerekmektedir. Dolayısıyla politik istikrar için gerekli yasal düzenlemeler yapılarak ekonomik büyümenin daha güçlü ve sürdürülebilir olması sağlanmalıdır.

\section{Kaynaklar}

Aisen, A., \& Veiga, F. J. (2006). Does political instability lead to higher inflation? A panel data analysis. Journal of Money, Credit, and Banking, 38(5), 1379-1389.

Alesina, A., Özler, S., Roubini, N., \& Swagel, P. (1996). Political instability and economic growth. Journal of Economic growth, 1(2), 189-211.

Arslan, Ü. (2011). Siyasi istikrarsızıı ve ekonomik performans: Türkiye örneği. Ege Akademik Bakıs, 11(1).

Asteriou, D., \& Price, S. (2000). Political instability and economic growth: UK time series evidence. Scottish Journal of Political Economy, 48(4), 383-399.

Beck, N., \& Katz, J. N. (1995). What to do (and not to do) with time-series cross-section data. American Political Science Review, 89(3), 634-647.

Bussiere, M., \& Mulder, C. (1999). Political instability and economic vulnerability. IMF Working Paper, WP/99/46.

Campos, N. F., \& Nugent, J. B. (2002). Who is afraid of political instability?. Journal of Development Economics, 67(1), 157-172.

Fair, R. C. (1978). The effect of economic events on votes for president. The Review of Economics and Statistics, 159173.

Feng, Y. (1997). Democracy, political stability and economic growth. British Journal of Political Science, 27(3), 391-418.

Fielding, D. (2003). Modelling political instability and economic performance: Israeli investment during the Intifada. Economica, 70(277), 159-186.

Fosu, A. K. (2001). Political instability and economic growth in developing economies: Some specification empirics. Economics Letters, 70(2), 289-294.

Gür, T. H., \& Arbulut, H. (2012). Gelismekte olan ülkelerde politik istikrarın ekonomik büyüme üzerine etkisi. Sosyoekonomi, (1), 281.

Hansen, C. B. (2007). Generalized least squares inference in panel and multilevel models with serial correlation and fixed effects. Journal of Econometrics, 140(2), 670-694.

Jong-A-Pin, R. (2006). On the measurement of political instability and its impact on economic growth. European Journal of Political Economy, 25(1), 15-29.

Kramer, G. H. (1971). Short-term fluctuations in US voting behavior, 1896-1964. American political science review, 65(1), 131-143.

Lensink, R., Hermes, N., \& Murinde, V. (2000). Capital flight and political risk. Journal of International Money and Finance, 19(1), 73-92.

North, D. C. (1991). Institutions STÖR. The Journal of Economic Perspectives, 5(1), 97-112.

Mamunur Rashid, Xuan Hui Looi, Shao Jye Wong, (2017) Political stability and FDI in the most competitive Asia Pacific countries, Journal of Financial Economic Policy, Vol. 9 Issue: 02, pp.140-155, https://doi.org/10.1108/JFEP-032016-0022

Shahrokhi, M., Cheng, H., Dandapani, K., Figueiredo, A., Parhizgari, A. M., \& Shachmurove, Y. (2017). The evolution and future of the BRICS: Unbundling politics from economics. Global Finance Journal, 32, 1-15.

Tang, C. F., \& Abosedra, S. (2014). The impacts of tourism, energy consumption and political instability on economic growth in the MENA countries. Energy Policy, 68, 458-464.

Taylor, W. E. (1977). Small sample properties of a class of two stage Aitken estimators. Econometrica: Journal of the Econometric Society, 497-508.

Tosun, M. U., Gran, M. C., \& Ulucan, A. (2008). The political instability, investment profile and the macroeconomic performance of the Middle East and North Africa (MENA) Region. Problems and Perspectives in Management, 6(2), 31-38.

White, S., McAllister, I., \& Munro, N. (2017). Economic inequality and political stability in Russia and China. Europe-Asia Studies, 69(1), 1-7. 